\title{
As guardiãs da saúde: representações e características socioculturais de enfermeiras domésticas do Rio de Janeiro, 1880-1910
}

\author{
The guardians of health: representations and sociocultural \\ characteristics of domestic nurses in Rio de Janeiro, 1880-1910
}

\section{Luiz Otávio Ferreira*}

Resumo: O objetivo deste artigo é descrever e analisar as representações e as características socioculturais das mulheres que trabalhavam como enfermeiras em domicílios, hospitais e asilos na cidade do Rio de Janeiro no final do século XIX e início do século XX. Conforme apresentadas em anúncios em matéria de oferta e de procura de serviços de enfermagem, publicados no conhecido diário carioca o Jornal do Commercio entre 1880 e 1910.

Palavras-chave: enfermeira; trabalho doméstico; saúde.

\begin{abstract}
The aim of this article is to describe and analyze the representations and sociocultural characteristics of women who worked as nurses in homes, hospitals and nursing homes in the city of Rio de Janeiro in the late 19 th and early 20 th centuries. As presented in announcements regarding the supply and demand of nursing services published, between 1880 and 1910, in the well-known Carioca daily Jornal do Commercio.
\end{abstract}

Keywords: nurse; housework; health.

\footnotetext{
Doutor em História pela Universidade de São Paulo (USP). Pesquisador titular do Departamento de História das Ciências e da Saúde e docente do Programa de Pós-graduação em História das Ciências e da Saúde da Casa de Oswaldo Cruz (FIOCRUZ). Professor associado do Departamento de Ciências Sociais e Educação da Faculdade de Educação da Universidade do Estado do Rio de Janeiro (UERJ). ORCID: https://orcid.org/00000002-7512-7343. E-mail: ulume2@gmail.com.
} 
O objetivo deste artigo é descrever e analisar as representações e as características socioculturais das mulheres que trabalhavam como enfermeiras em domicílios, hospitais e asilos na cidade do Rio de Janeiro no final do século XIX e início do século XX. Para isso, consultamos os anúncios de oferta e de procura de serviços de enfermagem publicados no conhecido diário carioca, o Jornal do Commercio, entre 1880 e 1910, considerando quatro pontos específicos: 1) a cor, a condição jurídica ou a nacionalidade; 2) os atributos físicos, etários, morais e culturais; 3) o tipo de cuidados e o tipo de clientela para quem seriam prestados os serviços; e 4) os locais ou ambientes de trabalho.

Naquela época, na cidade de Rio de Janeiro, chamava-se de enfermeiras um grupo heterogêneo de mulheres que compartilhavam status e experiência em comum, mas que era uma mistura diversificada de praticantes de diversas origens socioeconômicas e raciais. Eram mulheres livres ou escravas, brancas ou negras, brasileiras ou estrangeiras. A maioria não havia recebido nenhum tipo de educação específica para trabalhar como enfermeira. Embora a posse do diploma fosse um capital cultural que começava a ser valorizado, as mulheres enfermeiras não eram profissionais. Na verdade, a profissão de enfermagem não estava institucionalizada no país. As enfermeiras formavam um grupo específico incluído na categoria dos ofícios domésticos. As enfermeiras compartilhavam as mesmas experiências de trabalho vivenciadas pelas amas de leite, mucamas, damas de companhia ou governantas. Faziam parte do grande contingente de trabalhadoras conhecido como criadas domésticas, formado por "mulheres escravas, mas também libertas, livres, brancas, empobrecidas". ${ }^{1}$

\section{Uma profissão de mulheres}

A HISTORIOGRAFIA MENCIONA que as chamadas "profissões de mulheres" surgem no final do século $\mathrm{XIX}$, quando se intensificou o ingresso de mulheres na indústria, no comércio, no serviço público e nas atividades de educação e de assistência. Foi um fenômeno marcado pela ideologização de gênero que atribuía às atividades laborais exercidas por mulheres o sentido de "prolongamento das funções 'naturais' maternais e domésticas". ${ }^{2}$ A profissão de enfermeira surge nesse contexto. As práticas de cuidados com os corpos dos doentes internados em hospitais e asilos, que até então estavam confiadas às religiosas (irmãs de caridade, freiras), são assumidas por mulheres qualificadas profissionalmente. Na Inglaterra, a enfermagem profissional foi implantada adotando o modelo desenvolvido por Florence Nightingale (1820-1910) no serviço de enfermagem das tropas do Império Britânico durante a Guerra da Criméia na década de 1850. Na vertente inglesa, a enfermagem se estabeleceu recrutando mulheres de classe média que emprestavam seu capital sociocultural para legitimar a profissão, garantindo, assim, autonomia e prestígio. $\mathrm{Na}$

1 TELLES, Lorena Féres da Silva. Amas de Leite. In: SCHWARCZ, Lilia Moritz; GOMES, Flávio dos Santos (org.). Dicionário da escravidão e liberdade: 50 textos críticos. São Paulo: Companhia das Letras, 2018. p. 99.

2 PERROT, Michelle. As mulheres e os silêncios da história. Tradução de Viviane Ribeiro. Bauru: EDUSC, 2005. p. 252. 
França, a formação profissional de enfermeiras começa na década de 1880, em sintonia com o processo de laicização que excluiu as religiosas dos hospitais parisienses. Mas, diferente da experiência inglesa, as enfermeiras francesas foram recrutadas entre mulheres pobres e com pouca educação escolar. As enfermeiras francesas eram menos qualificadas e mais submissas aos médicos. Mas o que se deve destacar é que a obtenção do diploma transformava a enfermagem de serviço doméstico numa profissão baseada na qualificação e no salário. ${ }^{3}$

$\mathrm{Na}$ busca por informações sobre os serviços de enfermeiras, encontramos no Jornal do Commercio uma matéria que tratava da enfermagem como uma opção digna de trabalho para as mulheres educadas. Intitulada "O que virá a ser a nossa filha?", ${ }^{4}$ a matéria comentava a "curiosa brochura" do escritor alemão Herr Wild-Queisner que abordava o sensível tema da profissionalização de mulheres. O escritor alemão mostrava-se favorável à modernização da educação oferecida às mulheres, aconselhando que, ao "invés de piano, de canto e desenho", as jovens senhoritas deveriam estudar geografia, cálculo matemático e praticar "muita ginástica para endurecer o corpo e torná-lo resistente às fadigas da vida". O modelo de educação proposto não distinguia a formação escolar da do trabalho doméstico, que deveria ser uma atividade complementar realizada "no seio de outra família", ou seja, em ambiente afastado do grupo familiar de origem. O objetivo seria dar às jovens mulheres a experiência prática necessária na administração da vida doméstica. Também divulgava as vantagens do novo tipo de educação que, segundo Herr Wild-Queisner, iriam bem além do simples preparativo para o eventual matrimônio, credenciando as senhoritas para o exercício de algumas das 32 profissões consideradas como "acessíveis às mulheres". Eis a lista de profissões organizada conforme seis tipos distintos (Quadro 1):

\section{Quadro 1 - Lista de profissões "acessíveis” às mulheres.}

\begin{tabular}{|l|l|}
\hline Profissões domésticas & $\begin{array}{l}\text { Dama de companhia, governanta, intendente ou mordoma, inspetora } \\
\text { de jardim de crianças, enfermeira }\end{array}$ \\
\hline Profissões comerciais & $\begin{array}{l}\text { Caixa, guarda-livros, caixeira de armazém, modista de chapéus, } \\
\text { costureira, viajante de comércio, gerente }\end{array}$ \\
\hline Profissões públicas & $\begin{array}{l}\text { Empregada de caminhos de ferro, telegrafista, empregada de } \\
\text { telefone, professora }\end{array}$ \\
\hline Profissões científicas & Médica, advogada ou filósofa, agrônoma, jornalista, dentista \\
\hline Profissões artísticas & Mestra de música, pintora, atriz, escritora \\
\hline Profissões industriais & $\begin{array}{l}\text { Pintora de porcelana, pintora de vidro, pintora de tecidos, florista, } \\
\text { litógrafa, mestra de dança, fotógrafa }\end{array}$ \\
\hline
\end{tabular}

Fonte: O QUE virá a ser a nossa filha? Jornal do Commercio. Rio de Janeiro, 16 nov. 1897. p. 1. Disponível em: http://bndigital.bn.gov.br/hemeroteca-digital/. Acesso em: 26 jun. 2020.

3 Idem. Minha história das mulheres. Tradução de Ângela Correia. São Paulo: Contexto, 2017. p. 125.

4 O QUE virá a ser a nossa filha? Jornal do Commercio, Rio de Janeiro, p. 1, 16 nov. 1897. Disponível em: http://bndigital.bn.gov.br/hemeroteca-digital/. Acesso em: 26 jun. 2020. 
No Brasil, no final do século XIX, as chances de uma mulher exercer alguma das 32 profissões "acessíveis às mulheres" eram muito reduzidas. O trabalho das mulheres - livres ou escravas - estava confinado ao âmbito da economia doméstica. O acesso restrito à educação escolar limitava ao extremo o número de mulheres atuando em algum tipo de profissão que exigisse algum tipo de qualificação formal. Analisando os dados do primeiro censo populacional brasileiro, realizado em 1872, Eni de Mesquita Samara ${ }^{5}$ mostrou que o número de mulheres trabalhadoras era expressivo em três categorias: no serviço doméstico, que absorvia o maior contingente de mulheres; nas ocupações relacionadas à agricultura, que registrava a presença de lavradoras; e nas ocupações fabris, com destaque para as operárias em tecido. Em número bem menor, registrou-se a presença de mulheres atuando como artistas (artesãs), capitalistas e proprietárias, parteiras e professoras. As enfermeiras não foram citadas, mas acreditamos que compusessem o imenso contingente de mulheres que atuavam no serviço doméstico.

NoBrasil a enfermagem torna-se uma profissão legalmente reconhecida com a publicação do Decreto n. ${ }^{\circ} 791$, de 27 de setembro de 1890, do governo provisório da República, que criou a Escola de Enfermeiros e Enfermeiras vinculada ao Hospício Nacional de Alienados, o antigo Hospício de Pedro II. O decreto definiu que para serem admitidos na escola profissional os homens e as mulheres interessados deveriam ter no mínimo 18 anos de idade, saber ler e escrever corretamente, dominar as quatro operações aritméticas e apresentar um atestado de "bons costumes". Para obter o diploma, era necessário frequentar a escola por dois anos no mínimo. O currículo que orientava a formação dos futuros enfermeiros e enfermeiras incluía noções básicas de medicina, higiene e administração hospitalar. A novidade era o regime de internato hospitalar, modalidade que oferecia aos estudantes aposentos, alimentação e uma remuneração de $20 \$$ ou de $30 \$$, conforme a progressão no curso. Outra vantagem era que os diplomados teriam preferência para os empregos em hospitais públicos e direito a aposentadoria depois de 25 anos de serviço. ${ }^{6}$

A historiografia acompanhou o surgimento de outras escolas de enfermagem. Entre 1890 e 1920 foram criados 27 estabelecimentos de ensino de enfermagem, nas cidades de São Paulo, Rio de Janeiro e Recife, e, destes, apenas cinco não foram efetivamente implantados. ${ }^{7}$ As aulas e o treinamento prático eram ministrados em hospitais públicos e privados. Ainda que se registre a contratação de algumas enfermeiras diplomadas nos Estados Unidos, Inglaterra, França e Alemanha para atuarem como professoras, o corpo docente era constituído

5 SAMARA, Eni Mesquita. Mão de obra feminina, oportunidades e mercado de trabalho no Brasil do século XIX. In: SAMARA, Eni Mesquita (org.). As ideias e os números do gênero: Argentina, Brasil e Chile no século XIX. São Paulo: Editora HICITEC, 1997. p. 49.

6 MINISTÉRIO DA SAÙDE. Enfermagem (Leis, Decretos e Portarias). $2^{\mathrm{a}}$ ed. rev. e aum. Rio de Janeiro: Serviço Especial de Saúde Pública, 1959. p. 1-2.

7 MOTT, Maria Lúcia; OGUISSO, Taka. Discutindo os primórdios do ensino de enfermagem no Brasil: o Curso de Enfermagem da Policlínica de Botafogo (1917-1920). Revista Paulista de Enfermagem, São Paulo, v. 22, n. 1, p. 82-92, 2003; MOTT, Maria Lúcia. Revendo a história da enfermagem em São Paulo (1890-1920). Cadernos Pagu, Campinas, v. 13, n. 1, p. 327-355, 1999; MOTT, Maria Lúcia; TSUNECHIRO, Maria Alice. Os cursos de enfermagem da Cruz Vermelha Brasileira e o início da enfermagem profissional no Brasil. Revista Brasileira de Enfermagem, Brasília, v. 55, n. 5, p. 592-599, 2002. 
basicamente de médicos que demonstravam estarem razoavelmente bem informados sobre o novo método (padrão Nightingale) de formação profissional em enfermagem.

O funcionamento das primeiras escolas desencadeou a mudança do perfil sociocultural e de gênero dos praticantes da enfermagem. Como já salientamos, no Rio de Janeiro oitocentista a enfermagem era uma atividade praticada indistintamente por homens e mulheres. Com exceção das irmãs de caridade, a maioria absoluta dos enfermeiros e das enfermeiras não havia recebido qualquer tipo de treinamento específico. Mas, a maioria das escolas de enfermagem foi frequentada exclusivamente por mulheres escolarizadas, acarretando a elevação do nível sociocultural das praticantes e a criação de condições sociais básicas para consolidação da profissão.

Entre os médicos firmava-se o consenso de que, para atuarem como enfermeiras, as mulheres deveriam ser submetidas a um ciclo de preparação técnica. Não seriam, portanto, quaisquer mulheres que estariam aptas a exercer profissionalmente a enfermagem. As escolas de enfermagem selecionavam somente as mulheres culturalmente capazes de se adaptar às exigências do novo regime de formação profissional. Com duração média variando entre um e dois anos, os cursos de enfermagem ensinavam noções básicas de anatomia, fisiologia, higiene, assistência médica e assistência cirúrgica. As atividades práticas eram realizadas nas enfermarias dos hospitais. Quando estavam submetidas ao regime de internato, as alunas residiam nos hospitais. Exigia-se das futuras enfermeiras que soubessem ler, escrever e executar com destreza as operações aritméticas. Além disso, elas deveriam adotar determinadas condutas e hábitos, tais como manter-se em boa condição de saúde, preservar a idoneidade moral, ser jovem e preferencialmente solteira. Em alguns casos, exigia-se que as alunas demostrassem competência em inglês e francês.

A historiografia que estamos citando não define com exatidão a origem social e o nível de escolaridade predominante entre as alunas, mas cita que moças de elite de São Paulo e do Rio de Janeiro faziam parte da clientela das escolas de enfermagem. O mais provável é que o perfil socioeconômico das alunas variasse conforme as exigências educacionais e culturais impostas por cada uma das escolas. Supomos que as escolas de enfermagem tenham sido frequentadas por mulheres de diferentes origens socioeconômicas e raciais. No entanto, o pequeno número de enfermeiras efetivamente diplomadas - as turmas quase sempre tinham menos do que dez alunas - pode ser um indício de que acesso à enfermagem profissional estava restrito a determinados grupos sociais.

\section{As guardiãs da saúde}

A IMPLANTAÇÃO DE ESCOLAS de formação profissional estimulava a publicação de livros que pudessem ser utilizados como material de apoio pedagógico. É o caso do Livro do enfermeiro 
e da enfermeira - para uso dos que se destinam à profissão das pessoas que cuidam de enfermos, de autoria de Getúlio F. dos Santos, médico do Serviço Sanitário do Exército e da Cruz Vermelha Brasileira. Embora fosse apresentado como "uma espécie de vade mecum, guia do enfermeiro e de toda pessoa que se veja na contingência de auxiliar o médico nas curas dos que sofrem, ou que por espontânea vontade o queira fazer", ${ }^{8}$ na prática, o livro era o manual adotado na escola das enfermeiras da Cruz Vermelha Brasileira criada em 1910. ${ }^{9}$

Para o médico Getúlio dos Santos, as mulheres que, equivocadamente, eram chamadas de enfermeiras seriam "senhoras, ordinariamente de idade já madura", desprovidas da "menor noção científica dos fatos com que diariamente lidam", que já haviam perdido "o viço e a fortaleza da mocidade" e que muitas vezes tinham sido recrutadas entre as "antigas serventes ou enfermas inválidas" que permaneciam nos hospitais. A predominância de mulheres de origem popular afugentaria da profissão o "elemento feminino" educado. A enfermagem caminharia em direção oposta à seguida pelo magistério que, naquele período, atrairia a "pletora de candidatas aos cargos de professorado primário". ${ }^{10}$

A enfermeira imaginada pela medicina higienista é descrita, em detalhes, no Livro do enfermeiro e da enfermeira. A mulher ideal para se tornar enfermeira profissional deveria possuir predicados físicos, sanitários, intelectuais e morais bem específicos. Deveria "ser de boa organização e suficientemente robusta" para que fosse capaz de suportar as prolongadas e fatigantes jornadas de trabalho à cabeceira do leito dos doentes. Além de robusta, era indispensável que fosse sadia e higiênica, pois "as pessoas que exercem essa profissão têm necessidade de se preocuparem com o máximo cuidado pela conservação de sua saúde". A enfermeira adotaria hábitos rigorosos de higiene pessoal. A roupa de trabalho (o uniforme) deveria ser de cor branca, a "cor pela qual menos se pode ocultar qualquer parcela de desasseio". A limpeza diária do corpo com "água e sabão" deveria ser uma prática obrigatória. A boa enfermeira deveria estar ciente de que, sobre a pele, "abundam micro-organismos ou micróbios de várias espécies". Igualmente metódica deveria ser a higiene bucal feita com a escovação dos dentes após as refeições. ${ }^{11}$

A capacidade intelectual da mulher que desejasse ser uma enfermeira deveria ser mediana, o "suficiente para que ela compreenda facilmente os ensinamentos que the forem ministrados, de modo que possa aplicar inteligentemente o que the for determinado pelo médico para o tratamento e cura do enfermo". E, sobretudo, a mulher ideal para o exercício da profissão deveria ter certas qualidades morais tidas como essenciais: "calma, precisão, atenção, espírito de observação, regularidade, rapidez na execução, paciência, autoridade e, finalmente, bondade, coragem e devotamento". ${ }^{12}$

8 SANTOS, Getúlio F. Livro do enfermeiro e da enfermeira: para uso dos que se destinam à profissão das pessoas que cuidam de enfermos. Rio de Janeiro: Typ. do Jornal do Commercio, de Rodrigues \& C., 1916. p. 4.

9 MOTT; TSUNECHIRO, op. cit.

10 Ibidem, p. 8.

11 Ibidem, p. 22-37.

12 Ibidem, p. 15-16. 
Após fazer a descrição minuciosa dos atributos físicos e socioculturais desejáveis, o médico Getúlio dos Santos não surpreende quando defende que a enfermeira profissional deveria trabalhar, de preferência, em "casa de família", em ambiente doméstico. Para ele, os hospitais do Rio de Janeiro não possuíam serviços de enfermagem adequadamente organizados e, por isso, não ofereciam às enfermeiras bem preparadas as condições de trabalho minimamente adequadas. Os ambientes hospitalares eram precários e poriam em risco a reputação das enfermeiras profissionais que por lá se aventurassem. Para não serem confundidas com as curiosas (parteiras ou enfermeiras sem formação profissional), a recomendação era que as enfermeiras se dedicassem à "assistência privada, em contato com as famílias". No ambiente doméstico e familiar, as enfermeiras teriam acesso "às [mesmas] comodidades de que gozam em seu lar, com o respeito que sua instrução deve impor e o tratamento que sua educação merece", além de condições seguras para praticar os seus conhecimentos e as habilidades profissionais. Idealmente, portanto, deveria haver certa afinidade de classe social entre a enfermeira e a família contratante. Por adotarem os mesmos valores e hábitos dos seus patrões, as enfermeiras estariam aptas para administrar a economia doméstica e para agir com amabilidade e circunspecção - "um delicado tato (savoir-faire, dos franceses)" - no convívio com as famílias dos enfermos assistidos. ${ }^{13}$

Aênfase atribuída ao papel doméstico e à conduta higiênica das enfermeiras relaciona-se às transformações do padrão de relacionamento entre as criadas domésticas e patrões e patroas, afetado com a abolição do trabalho escravo e com a adoção de um estilo de vida moderno por parte das elites urbanas cariocas. ${ }^{14} \mathrm{~A}$ modernização material e cultural da vida familiar, assentada em recomendações da medicina higienista, redefinia os papéis femininos no ambiente doméstico, pondo ênfase naqueles relacionados à maternidade (gestação, criação e educação dos filhos) e aos cuidados com a saúde dos membros da família. As mulheres da elite são orientadas a selecionar criteriosamente suas criadas, sob a alegação de que a presença delas no ambiente doméstico constituía um sério risco para a saúde e para a moralidade das famílias. A tensão social e racial entre os patrões e as criadas se traduzia na produção de representações negativas a respeito das mulheres que tradicionalmente trabalhavam como amas de leite, lavadeiras, arrumadeiras ou cozinheiras. ${ }^{15}$ No imaginário de mães e esposas da elite carioca, desenhava-se um novo tipo de criada doméstica que espelhava as enfermeiras profissionais: sadia, higiênica, intelectualmente segura e moralmente confiável.

13 Ibidem, p. 14, 20-21.

14 GRAHAM, Sandra Lauderdale. Proteção e obediência: criadas e seus patrões no Rio de Janeiro, 1860-1910. São Paulo: Companhia das Letras, 1992; RONCADOR, Sonia. O demônio familiar: lavadeiras, amas de leite e criadas na narrativa de Júlia Lopes de Almeida. Luso-Brazilian Review, Madison, v. 44, n. 1, p. 94-119, 2007.

15 MACHADO, Maria Helena P. T. Entre dois Beneditos: história de amas de leite no ocaso da escravidão. In: XAVIER, Giovana; FARIAS, Juliana Barreto; GOMES, Flavio dos Santos (org.). Mulheres negras no Brasil escravista e do pós-emancipação. São Paulo: Selo Negro, 2012. p. 199-213; TELLES, Lorena Féres da Silva. Libertas entre sobrados: mulheres negras e trabalho doméstico em São Paulo (1880-1920). São Paulo: Alameda, 2013. 
O estilo de vida higiênico adotado pela elite carioca motivava as mulheres a assumirem a responsabilidade pelos cuidados de saúde com a adoção de práticas que acreditavam fossem garantir a saúde e o bem-estar de seus filhos, maridos e parentes idosos. Como a internação em hospitais não era uma decisão costumeira, cabia às mulheres o papel de "guardiãs da saúde": "A mulher cuida pessoalmente de 'seus doentes' ministrando alimentação e remédios adequados sem receios, já que os doentes reagem contra a tentativa de contratar enfermeiras profissionais para seus cuidados. ${ }^{16}$

A "terapêutica doméstica" adotada pelas "guardiãs da saúde" mesclava preceitos tradicionais e modernos. O contato com a natureza e a boa alimentação eram considerados fundamentais no tratamento de qualquer tipo de doença. Os banhos de mar, as temporadas em regiões serranas ou o recurso à hidroterapia em balneários conhecidos como "estação de águas" faziam parte do repertório terapêutico adotado pela elite urbana. Os remédios caseiros e a farmacologia médica eram igualmente utilizados. As mulheres e mães eram estimuladas a consumirem as drogas anunciadas pela publicidade estampada nos jornais. Ao mesmo tempo em que eram influenciadas pelos médicos, elas também seguiam as orientações de farmacêuticos e parteiras. Era para atuar nesse tipo de ambiente doméstico de cultura híbrida, que combinava tradição e modernidade, no que concerne aos cuidados com a saúde, que as enfermeiras eram contratadas para auxiliar ou, mais provavelmente, para desempenhar elas mesmas o papel de "guardiãs da saúde" sob a supervisão das suas patroas.

\section{Enfermeiras domésticas}

As CARACTERÍSTICAS SOCIOCULTURAIS das enfermeiras domésticas que iremos analisar em seguida não correspondem às expectativas dos médicos e das famílias conforme descritas até aqui. Poucas delas afirmavam serem enfermeiras diplomadas em escolas. Embora o trabalho exercido em ambiente doméstico fosse uma condição quase unânime entre elas, as mulheres que trabalhavam como enfermeiras formavam um grupo social diversificado.

Para produzirmos o quadro sobre as características socioculturais das mulheres que trabalhavam como enfermeiras, computamos a frequência de quatro conjuntos de informações frequentes nos anúncios de "compra e venda" de serviços domésticos: 1) a cor, a condição jurídica e a nacionalidade; 2) os atributos físicos, a faixa etária, os valores morais e culturais; 3) o tipo de cuidados e o tipo de clientela para quem seriam prestados os serviços; e 4) os locais ou ambientes de trabalho.

Embora fosse possível extrair dos anúncios outras informações relacionadas às enfermeiras e seu trabalho, optamos por restringir o escopo de busca àquilo que

16 ARAÚJO, Rosa Maria Barboza. A vocação do prazer: a cidade e a família no Rio de Janeiro republicano. $2^{\mathrm{a}}$ ed. Rio de Janeiro: Rocco, 1995. p. 193. 
convencionalmente é entendido como sua atribuição principal: cuidar de doentes ou de pessoas que necessitavam de atenção especial, tais como idosos, crianças e parturientes.

O que pretendemos é expor o tipo social da enfermeira, considerando suas características raciais e étnicas, os requisitos ou qualidades que eram socialmente valorizados, os tipos de pacientes que eram normalmente atendidos e, finalmente, quais eram os ambientes ou locais de trabalho das enfermeiras. Os gráficos que apresentamos a seguir registram a frequência de aparição, nos anúncios, de cada uma das informações que escolhemos para serem analisadas. Portanto, o número de informações registradas não corresponde ao número de anúncios ou de mulheres. Um anúncio pode expor várias ou nenhuma informação relevante sobre a mulher que trabalhava como enfermeira.

De certo modo, seguimos a metodologia já adotada por outros historiadores que analisaram os anúncios de compra e venda de serviços de amas de leite,${ }^{17}$ e também nos orientamos pela ideia de que os anúncios expunham, em linguagem simples e direta, os valores e a cultura cotidiana vigentes nas grandes cidades brasileiras no final do século XIX. ${ }^{18}$

Na maioria das vezes, os anúncios analisados não citavam a cor, a condição jurídica ou a nacionalidade das mulheres que atuavam no mercado de serviços de enfermagem. $O$ que encontramos é uma descrição genérica: "Precisa-se de uma enfermeira", "Oferece-se" ou "Aluga-se" uma enfermeira. No entanto, mesmo que não sejam informações frequentes, quando os anúncios fazem menção, é possível perceber que a cor ou nacionalidade eram "qualidades" que tinham forte significado simbólico, servindo para diferenciar e hierarquizar as enfermeiras.

Não consideramos que as mulheres "de cor" ou de condição jurídica "livre ou escrava" fossem minoritárias entre as enfermeiras, pelo contrário. A condição de trabalho doméstico vinculada à enfermagem certamente tornava subentendido, na sociedade escravista carioca, que esse tipo de trabalho devesse ser exercido por mulheres pretas ou pardas, livres ou escravas (gráfico 1).

17 EL-KAREH, Almir Chaiban. Famílias adotivas, amas de leite e amas-secas e o comércio de leite materno e de carinho na Corte do Rio de Janeiro. Gênero, Niterói, v. 4, n. 2, p. 9-30, 2004; MARTINS, Bárbara Canedo R. Reconstruindo a memória de um ofício: as amas de leite no mercado de trabalho urbano do Rio de Janeiro (1820-1880). Revista de História Comparada, Rio de Janeiro, v. 6, n. 2, p. 138-167, 2002.

18 SCHWARCZ, Lilia Moritz. Retrato em branco e negro: jornais, escravos e cidadãos em São Paulo no final do século XIX. $2^{\mathrm{a}}$ ed. São Paulo: Companhia das Letras, 2017. p. 156. 
Gráfico 1 - Cor, condição jurídica e ou nacionalidade

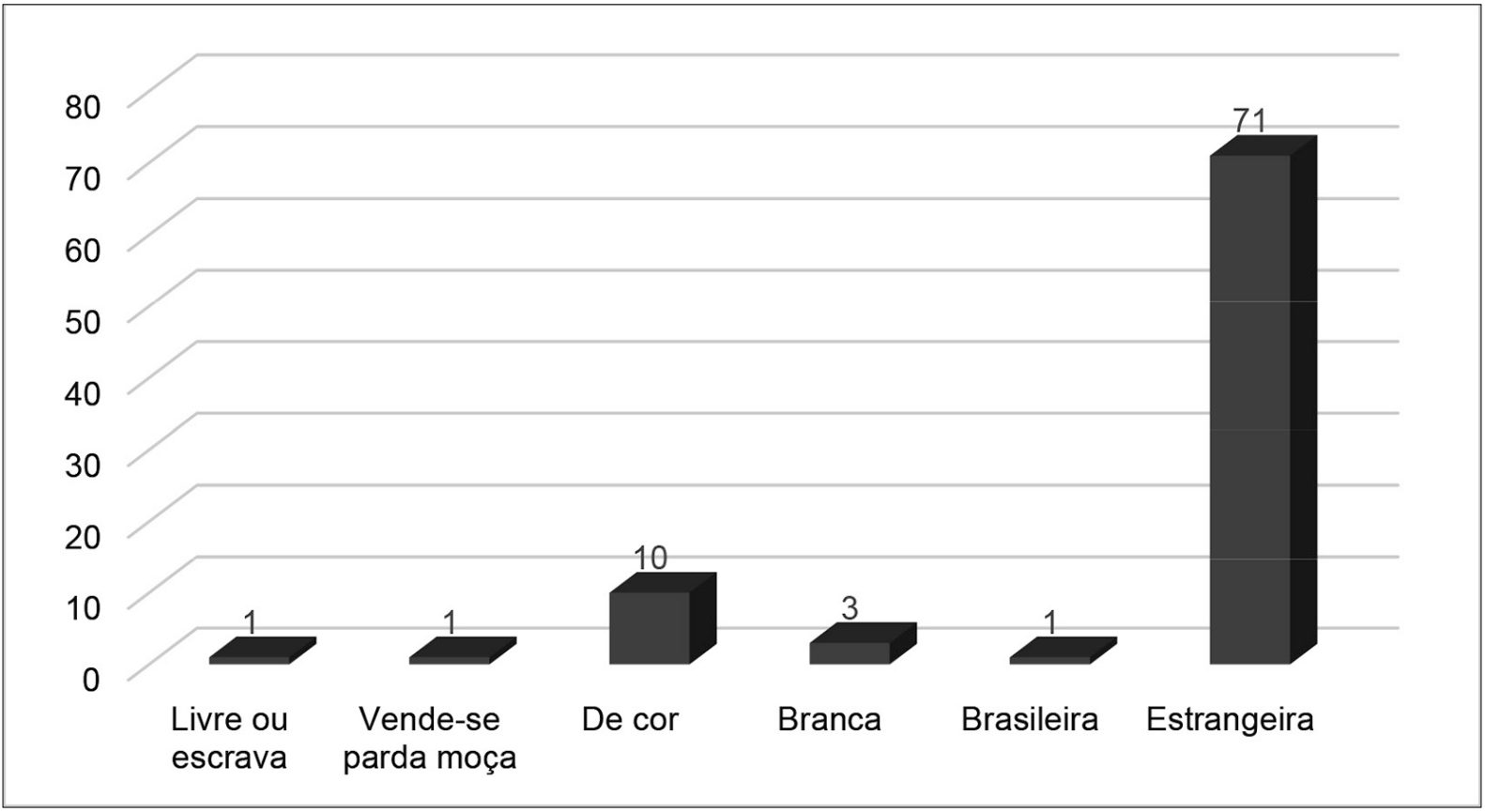

Fonte: elaboração própria baseada em anúncios veiculados pelo Jornal do Commercio (1880-1910).

Na década de 1880, os anúncios que requisitavam mulheres "de cor" não exigiam que elas tivessem experiência prática como enfermeiras, mas que já tivessem experiência trabalhando como criadas e "jeito" para se adaptarem à função de "cuidadora". Vejamos alguns exemplos: precisa-se de "uma mulher, parda ou preta" que esteja "acostumada a ser enfermeira";19 precisa-se de "uma senhora de meia-idade, livre ou escrava, que tenha paciência para tratar como enfermeira de um doente";20 precisa-se de "uma mulher de cor, e já de idade, que, abonando sua conduta, sirva para enfermeira de uma casa de família". ${ }^{21}$ Nos três exemplos citados, as habilidades exigidas das mulheres pretas e pardas requisitadas indicam que quem as requeria não considerava que os serviços prestados por uma enfermeira fossem distintos dos serviços habituais de uma criada doméstica.

Encontramos, na década de 1890, ofertas de trabalho para mulheres "de cor" que conciliavam explicitamente os serviços de enfermeira com a prestação de outros serviços domésticos como costurar, "tomar conta de casa" ou ser "preceptora de meninas". É o que indicam anúncios como esses: "uma senhora de cor, sabendo coser perfeitamente, deseja acompanhar uma família que se retire para o Norte, aceita também o lugar de enfermeira de uma senhora, mediante bom ordenado",22 "uma senhora de cor preta, dando fiador à sua

19 PRECISA-SE. Jornal do Commercio, Rio de Janeiro, p. 7, 7 ago. 1881. Disponível em: http://bndigital.bn.gov. br/hemeroteca-digital/. Acesso em: 26 jun. 2020.

20 PRECISA-SE. Jornal do Commercio, Rio de Janeiro, p. 6, 1 nov. 1881. Disponível em: http://bndigital.bn.gov. br/hemeroteca-digital/. Acesso em: 26 jun. 2020.

21 PRECISA-SE. Jornal do Commercio, Rio de Janeiro, p. 6, 3. abr. 1883. Disponível em: http://bndigital.bn.gov. br/hemeroteca-digital/. Acesso em: 26 jun. 2020.

22 UMA SENHORA de cor. Jornal do Commercio, Rio de Janeiro, p. 10, 3 maio 1896. Disponível em: http:// bndigital.bn.gov.br/hemeroteca-digital/. Acesso em: 26 jun. 2020. 
conduta, pretende um lugar de enfermeira de uma senhora ou preceptora de meninas";23 "uma senhora parda de meia-idade, casada, dedicada ao tratamento de enfermos, deseja empregar-se como uma enfermeira ou para tomar conta de casa de família". ${ }^{24}$ Nessas situações, trabalhar como enfermeira poderia ser uma tática utilizada pelas mulheres pretas e pardas para obterem alguma vantagem no concorrido mercado de trabalho das criadas.

As mulheres estrangeiras estavam presentes no mercado carioca de serviços de enfermagem. Ser "estrangeira" foi, de longe, a "qualidade" mais citada nos anúncios, quando consideramos exclusivamente as informações relativas à cor, condição jurídica ou a nacionalidade das mulheres. No entanto, a frequência de anúncios com referência à nacionalidade não significa que as mulheres imigrantes fossem maioria ou tivessem a preferência do público. A oferta constante de "enfermeiras estrangeiras" indica que elas se esforçavam para serem reconhecidas no mundo do trabalho das criadas domésticas, tradicionalmente dominado por mulheres pretas e pardas, livres ou escravas.

Encontramos anúncios que especificavam as nacionalidades: portuguesa, francesa, inglesa e alemã. Certamente o fluxo migratório de portuguesas, ${ }^{25}$ uma tradição relacionada à atuação local de parteiras francesas popularmente conhecidas como "madames", ${ }^{26}$ a prestigiada origem inglesa da enfermagem moderna e o gosto da elite carioca por governantas alemãs são fatores que ajudam a explicar a presença de estrangeiras. No entanto, como observaram Sandra Graham ${ }^{27}$ e Natália Batista Peçanha, ${ }^{28}$ a tendência não era de aumento da participação de estrangeiras. Em 1872 a maioria dos empregados domésticos (67\%) servindo em casas de família no Rio de Janeiro era de brasileiros. No início do século XX, a proporção tinha aumentado: brasileiros (78\%) e estrangeiros (22\%).

Os anúncios que ofereciam os serviços de mulheres portuguesas ressaltavam que elas estavam dispostas a trabalhar em casas de família como damas de companhia, governanta, cozinheira, lavadeira, arrumadeira e como enfermeira. Chama atenção nesses anúncios a frequência de avisos como "não faz questão de moléstia" ou "trata de quaisquer moléstias", um indício de que as enfermeiras estrangeiras se recusavam a cuidar de pacientes acometidos por determinados tipos de doenças, certamente doenças contagiosas. Aparentemente as mulheres portuguesas eram menos letradas do que suas concorrentes francesas, inglesas ou alemãs, já que poucos anúncios fazem menção à sua escolaridade ou ao domínio de

23 UMA SENHORA de cor preta. Jornal do Commercio, Rio de Janeiro, p. 10, 6 mar. 1898. Disponível em: http:// bndigital.bn.gov.br/hemeroteca-digital/. Acesso em: 26 jun. 2020.

24 UMA SENHORA parda. Jornal do Commercio, Rio de Janeiro, p. 7, 9 abr. 1904. Disponível em: http:// bndigital.bn.gov.br/hemeroteca-digital/. Acesso em: 26 jun. 2020.

25 DA SILVA, Maria Beatriz Nizza. A mulher no contexto da imigração portuguesa no Brasil. Análise social, v. 22 , n. 92/93, p. 653-659, 1986.

26 SOUZA, Maria Lucia de Barros Mott. Parto, parteiras, parturientes: Mme. Durocher e sua época. 1998. Tese (Doutorado em História Social) - Faculdade de Filosofia, Letras e Ciências Humanas, Universidade de São Paulo, São Paulo, 1998

27 GRAHAM, op. cit., p. 17

28 PEÇANHA, Natália Batista. O serviço doméstico e o mundo do trabalho carioca: uma análise das relações de trabalho de criadas nacionais e estrangeiras na passagem do século XIX para o XX. Maracanan, Rio de Janeiro, n. 21, p. 11-28, 2019. 
outros idiomas. Os anúncios que oferecem os serviços de mulheres portuguesas expõem o mesmo tipo social da "senhora brasileira" que exemplifica o estereótipo das mulheres que trabalhavam como enfermeiras:

Uma senhora brasileira, casada, não sabendo ler, mas já tendo sido enfermeira, deseja empregar-se em algum hospital ou casa de saúde ou particular, ou para arrumar quartos; quem precisar, pode procurá-la no Catete, na rua Silveira Martins n. $44,2^{\circ}$ andar. $^{29}$

No quesito escolaridade, as mulheres de nacionalidade francesa, inglesa e alemã estavam, aparentemente, em vantagem em relação às brasileiras e portuguesas. Algumas delas declaravam ser poliglotas, capazes de se comunicar em mais de um idioma. Outras afirmavam que possuíam experiência prática de enfermagem hospitalar ou que conheciam os fundamentos do higienismo médico, fazendo crer que fossem enfermeiras diplomadas ou treinadas. É o que podemos constatar a partir de avisos como: "uma senhora francesa, que conhece perfeitamente as leis de higiene atual, oferece seus serviços como enfermeira"; 30 "uma senhora estrangeira, de meia-idade, para enfermeira, com bastante prática, tanto em hospitais como em casas de saúde";31 "uma francesa para enfermeira, com 12 anos de prática e diploma". ${ }^{32}$ Ao lado da experiência hospitalar, os anúncios insinuavam que as postulantes estrangeiras ao emprego poderiam também atuar como parteiras: "uma senhora estrangeira oferece seus serviços como enfermeira de mulher parturiente"; 33 "aluga-se uma senhora portuguesa, de meia-idade, para enfermeira, trata de todas as moléstias e trata também de senhoras de parto; 34 "inglesa muito distinta e carinhosa com muita prática de tratar de senhoras de parto oferece-se para as excelentíssimas famílias". ${ }^{35}$

Não importando a cor ou a nacionalidade, as mulheres que se ofereciam deveriam atender a determinadas expectativas ou preferências das famílias que desejavam contratá-las. Sem dúvida, a principal credencial exigida era que a mulher fosse uma "senhora".

Mas o que significava ser uma "senhora"? A reconstrução do tipo aponta para uma combinação de três atributos: a faixa etária (meia-idade), o estado civil (casada ou viúva) e a maturidade adquirida servindo como criada. Uma "senhora" deveria inspirar confiança e ter a "conduta afiançada", ser "carinhosa" e ter "bons costumes", e, é claro, por ter experiência ("com prática") comprovada.

29 UMA SENHORA brasileira. Jornal do Commercio, Rio de Janeiro, p. 12, 21 jan. 1894. Disponível em: http:// bndigital.bn.gov.br/hemeroteca-digital/. Acesso em: 26 jun. 2020.

30 ENFERMEIRA. Jornal do Commercio, Rio de Janeiro, p. 6, 31 dez. 1890. Disponível em: http://bndigital. bn.gov.br/hemeroteca-digital/. Acesso em: 26 jun. 2020.

31 ALUGA-SE. Jornal do Commercio, Rio de Janeiro, p. 9, 25 mai. 1895. Disponível em: http://bndigital.bn.gov. br/hemeroteca-digital/. Acesso em: 26 jun. 2020.

32 ALUGA-SE. Jornal do Commercio, Rio de Janeiro, p. 9, 18 jun. 1895. Disponível em: http://bndigital.bn.gov. br/hemeroteca-digital/. Acesso em: 26 jun. 2020.

33 ENFERMEIRA. Jornal do Commercio, Rio de Janeiro, p. 12, 29 set. 1895. Disponível em: http://bndigital. bn.gov.br/hemeroteca-digital/. Acesso em: 26 jun. 2020.

34 ALUGA-SE. Jornal do Commercio, Rio de Janeiro, p. 6, 21 jan. 1894. Disponível em: http://bndigital.bn.gov. br/hemeroteca-digital/. Acesso em: 26 jun. 2020

35 ENFERMEIRA. Jornal do Commercio, Rio de Janeiro, p. 8, 7 jan. 1908. Disponível em: http://bndigital. bn.gov.br/hemeroteca-digital/. Acesso em: 26 jun. 2020. 
A existência das escolas que diplomavam para a prática profissional da enfermagem não se refletiu nos anúncios. O diploma não era um capital cultural valorizado, sendo poucas as referências às mulheres com "habilitação" ou "formação". A ausência de escolaridade era a principal característica cultural das mulheres dedicadas aos cuidados dos doentes; poucas declararam saber ler e escrever e, algumas vezes, os anúncios avisavam que eram analfabetas (gráfico 2).

Gráfico 2 - Atributos físicos, etários, morais e culturais

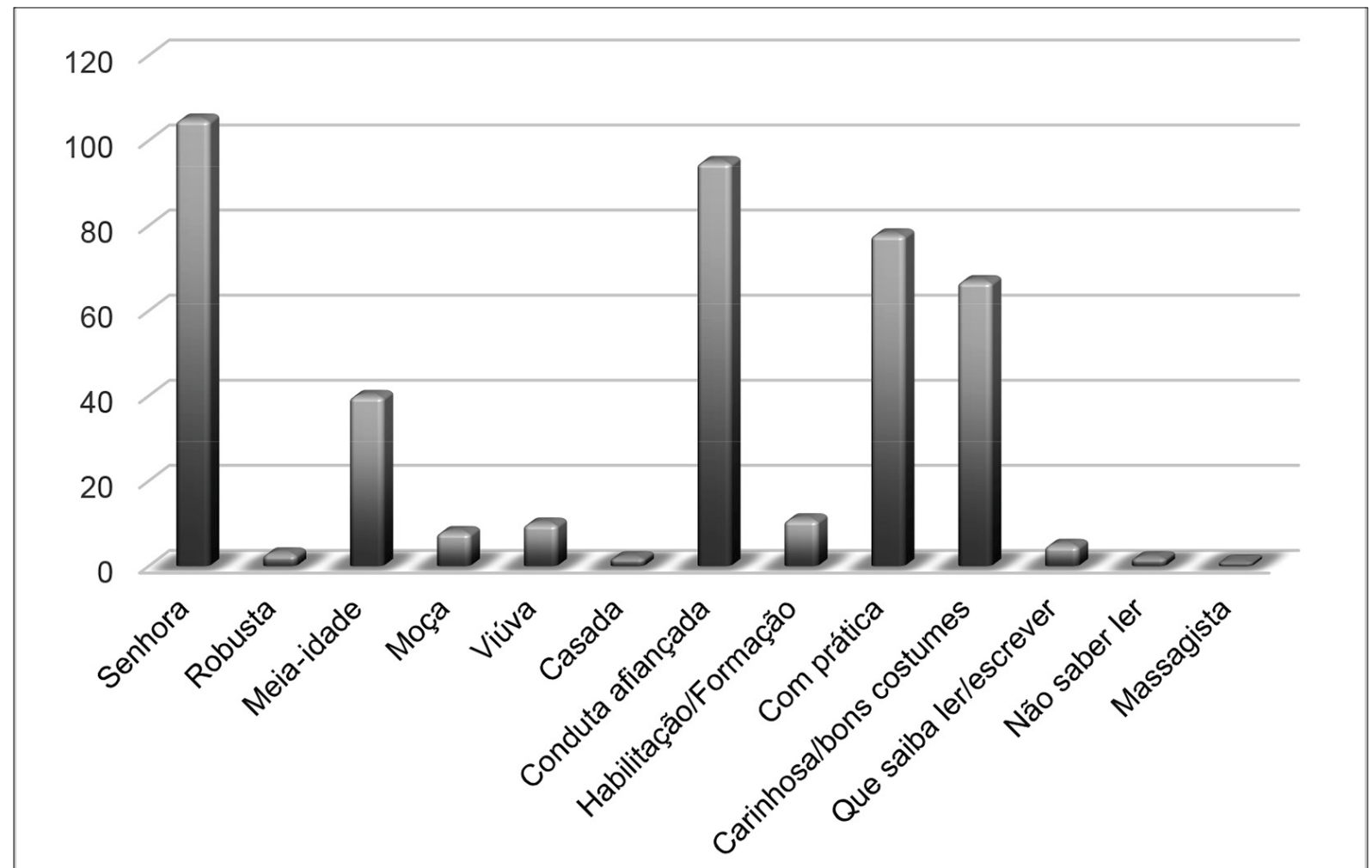

Fonte: elaboração própria baseada em anúncios veiculados pelo Jornal do Commercio (1880-1910).

A prática cotidiana das "senhoras" que trabalhavam como enfermeiras tinha um viés de gênero. A clientela era predominantemente feminina; eram mulheres que cuidavam de outras mulheres (gráfico 3). Já dissemos que era comum, especialmente entre as estrangeiras, a disponibilidade para cuidar de parturientes e crianças. O componente de gênero que marcava o trabalho das enfermeiras também se manifestava no fato de muitos anúncios exigirem que as criadas enfermeiras, além dos cuidados dedicados aos doentes, também se dedicassem a "outros serviços" domésticos como, por exemplo, os de damas de companhia, governanta, cozinheira, lavadeira e passadeira de roupas ou arrumadeira de quartos. Já citamos anteriormente que, às vezes, nos anúncios faziam-se advertências como "não cuida de loucos" ou, ao contrário, "que cuide de loucos", sinalizando que as enfermeiras poderiam se recusar a cuidar de enfermos acometidos de loucura e de doenças sabidamente contagiosas. 
Gráfico 3 - Tipos de cuidado e de clientela

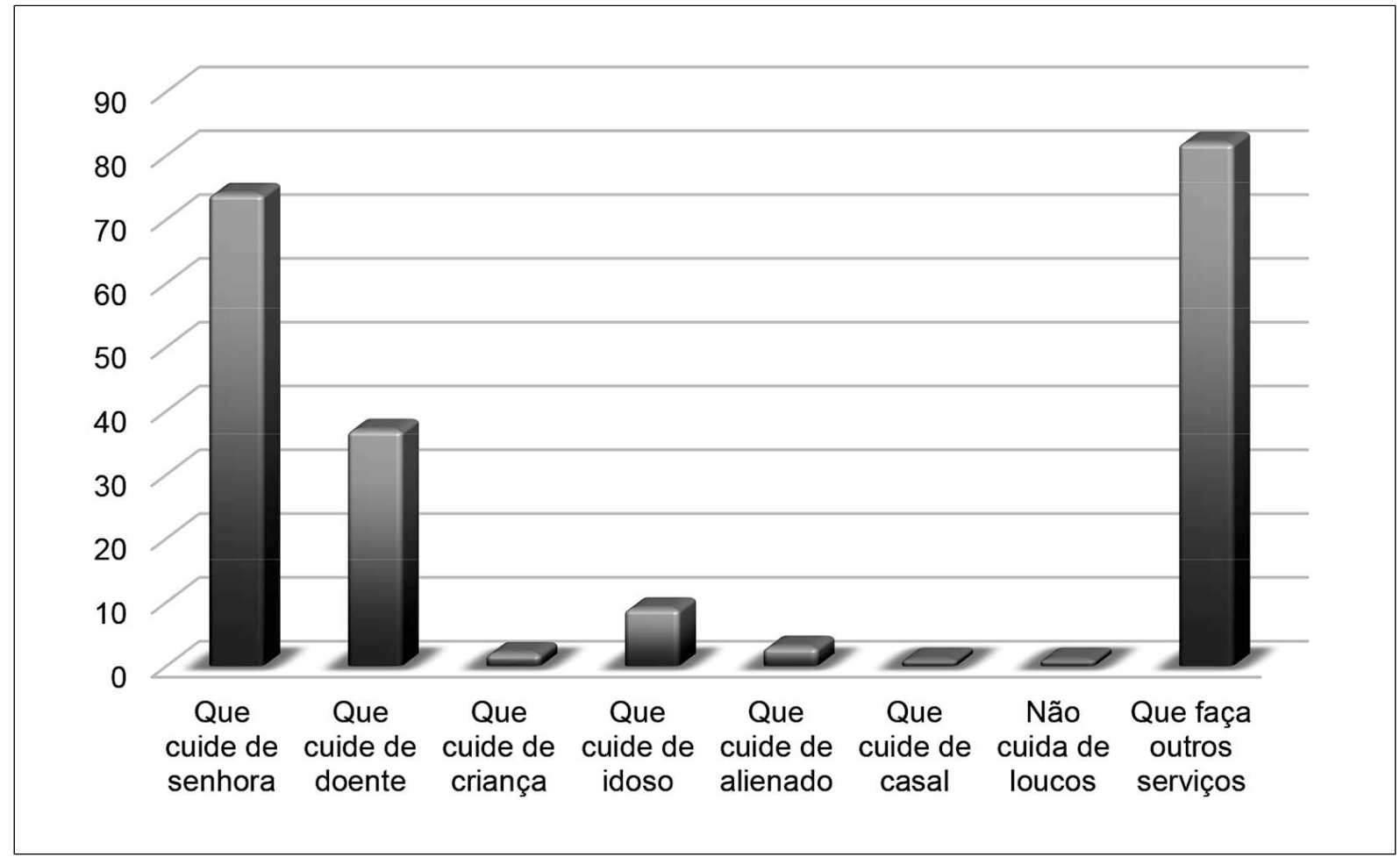

Fonte: elaboração própria baseada em anúncios veiculados pelo Jornal do Commercio (1880-1910).

Da mesma forma que Livro do enfermeiro e da enfermeira, ${ }^{36}$ já comentado, os anúncios confirmam que as "casas de famílias" eram o ambiente de trabalho mais comum das enfermeiras, fossem diplomadas ou não (gráfico 4). As menções são muito frequentes, mas pouco esclarecedoras, quanto ao salário ou remuneração que eram pagas às mulheres que trabalhavam como enfermeiras.

36 SANTOS, op. cit. 


\section{Gráfico 4 - Local de trabalho}

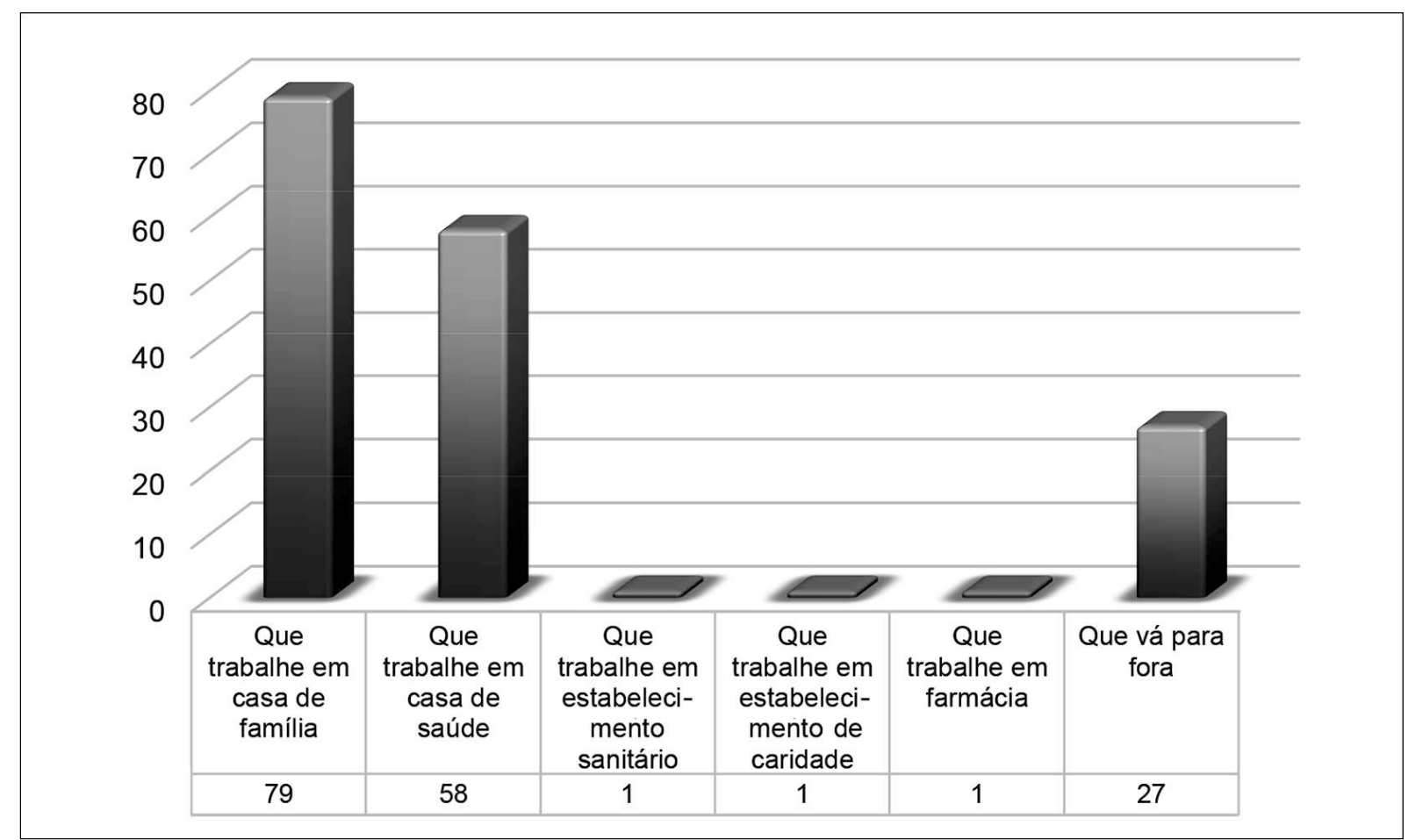

Fonte: elaboração própria baseada em anúncios veiculados pelo Jornal do Commercio (1880-1910).

No entanto, as ofertas de trabalho em hospitais, casas de saúde, instituições de caridade ou em farmácias também aparecem com frequência. Mesmo que timidamente, o processo de profissionalização da enfermagem já estava em curso criando novas oportunidades de trabalho para mulheres pobres. Após a publicação do já citado Decreto n. ${ }^{0} 791$, que criou uma escola de enfermeiros e enfermeiras no Hospital Nacional dos Alienados, o provedor da Santa Casa da Misericórdia enviou um ofício ao ministro do Interior consultando sobre a possiblidade de:

[...] meninas desvalidas [...] serem transferidas desse instituto para a assistência de asiladas maiores de 18 anos, a fim de se habilitarem para o exercício da profissão de enfermeiras [...]. Durante o aprendizado, as asiladas coadjuvarão os empregados da assistência no serviço que lhes for designado, e, na qualidade, algumas internas terão direito, além do aposento, a gratificação mensal de $20 \$$ no primeiro e de $25 \$$ no segundo ano. ${ }^{37}$

As gratificações mensais oferecidas para os alunos e alunas da escola de enfermagem eram muito baixas? Qual era o salário pago a uma enfermeira nas instituições de saúde ou de caridade? O valor do salário de uma enfermeira variava conforme o tipo instituição que se dispunha a contratá-la.

Não encontramos estudos que revelassem o nível de remuneração das mulheres que trabalhavam como enfermeiras em "casas de famílias". No artigo clássico de Eulália Lobo

37 ESCOLA de enfermeiras. Jornal do Commercio, Rio de Janeiro, p. 2, 23 out. 1890. Disponível em: http:// bndigital.bn.gov.br/hemeroteca-digital/. Acesso em: 26 jun. 2020. 
sobre categorias socioprofissionais, salários e custo de alimentação, as enfermeiras estão classificadas entre as categorias socioprofissionais de "nível intermediário", junto com os "ajudantes de enfermeiros", os cozinheiros e os porteiros. ${ }^{38}$ Citando os registros da Ordem Terceira de São Francisco da Penitência e da Santa Casa de Misericórdia do Rio de Janeiro de meados do século XIX, Eulália Lobo afirma que, nessas instituições, a maioria das enfermeiras era de irmãs de caridade e freiras ou escravas que não recebiam remuneração ${ }^{39} \mathrm{e}$, apontando para a predominância masculina nos hospitais, que "os salários dos enfermeiros ainda não sofriam a concorrência da enfermeira que recebia menos". ${ }^{40}$ Nos hospitais da Ordem Terceira e da Santa Casa, a ascensão da enfermeira estava relacionada à presença do administrador de hospital (normalmente um médico), uma profissão nova que apareceu por volta de 1875 em consequência do aumento da população e do esforço de saneamento da cidade. ${ }^{41}$

No Asilo de Mendicidade, órgão de assistência vinculado à Diretoria de Higiene e Assistência Pública da Prefeitura do Rio de Janeiro, criado em 1875, que se destinava a acolher mendigos idosos inválidos para o trabalho e doentes mentais que não fossem acolhidos no Hospício Nacional de Alienados, ${ }^{42}$ o salário pago a uma enfermeira era seiscentos mil réis (600\$000), o mesmo salário do cozinheiro. Na mesma instituição, o médico recebia bem mais, dois contos de réis $(2: 000 \$ 000) .{ }^{43} \mathrm{Na}$ Casa de São José, um orfanato para meninos desvalidos mantido pela mesma Diretoria de Higiene e Assistência Pública, os vencimentos das enfermeiras eram maiores, um conto e duzentos réis (1:200\$000); e, para termos uma base de comparação, citamos que os professores de instrução primária daquela instituição recebiam quatro contos e oitocentos réis $(4: 800 \$ 000) .{ }^{44}$ Em instituições de caridade, o valor do salário também variava. No Hospital de São João Batista de Niterói, os vencimentos estavam estipulados em oitenta e três mil réis $(83 \$ 000)$ para a enfermeira e em cem mil réis $(100 \$ 000)$ para o médico. ${ }^{45}$ No Hospital de Santa Teresa de Petrópolis, a enfermeira recebia quarenta mil réis $(40 \$ 000)$ e o $1^{\circ}$ enfermeiro recebia cento e vinte mil réis $(120 \$ 000) .{ }^{46}$

38 LOBO, Eulalia Maria Lahmeyer et al. Estudo das categorias socioprofissionais, dos salários e do custo da alimentação no Rio de Janeiro de 1820 a 1930. Revista Brasileira de Economia, Rio de Janeiro, v. 27, n. 4, p. 129-176, 1973. p. 132.

39 Ibidem, p. 146.

40 Ibidem, p.147.

41 Ibidem, p.170.

42 SIQUEIRA GONÇALVES, Monique de. Pelas ruas da cidade: Mendicidade, vadiagem e loucura na corte imperial (1850-1889). Tempos Históricos, Marechal Cândido Rondon, v. 20, n. 1, p. 154-188, 2016.

43 INFORMAM-NOS. Jornal do Commercio, Rio de Janeiro, p. 1, 20 nov. 1890. Disponível em: http://bndigital. bn.gov.br/hemeroteca-digital/. Acesso em: 26 jun. 2020.

44 INFORMAM-NOS. Jornal do Commercio, Rio de Janeiro, p. 1, 20 nov. 1890. Disponível em: http://bndigital. bn.gov.br/hemeroteca-digital/. Acesso em: 26 jun. 2020.

45 PAGAMENTOS autorizados. Jornal do Commercio, Rio de Janeiro, p. 4, 23 set. 1899. Disponível em: http:// bndigital.bn.gov.br/hemeroteca-digital/. Acesso em: 26 jun. 2020.

46 INFORMAM-NOS. Jornal do Commercio, Rio de Janeiro, p. 1, 20 nov. 1890. Disponível em: http://bndigital. bn.gov.br/hemeroteca-digital/. Acesso em: 26 jun. 2020. 


\section{Considerações finais}

As CARACTERÍSTICAS SOCIOCULTURAIS das mulheres que trabalhavam como enfermeiras, conforme descritas nos anúncios e matérias publicadas no Jornal do Commercio entre 1880 e 1910, indicam que elas compunham o grupo social mais amplo, que reunia as criadas domésticas, que reunia mulheres escravas e libertas, pretas, pardas e brancas, brasileiras e estrangeiras, pobres em sua maioria. As enfermeiras domésticas possuíam algumas características específicas. As mulheres estrangeiras estavam representadas no mercado de trabalho das enfermeiras domésticas, mas certamente não constituíam a maioria, nem eram as mais requisitadas.

$\mathrm{Na}$ maioria das vezes, as enfermeiras são referidas como "senhoras", termo que corresponderia a mulheres de meia-idade, casadas ou viúvas com larga experiência servindo como criadas. Havia nítido sentido de gênero relacionado ao trabalho de enfermeiras. A clientela era quase sempre formada por outras mulheres, senhoras adoecidas, idosas ou gestante. Mulheres cuidavam de mulheres.

A criação de escolas de enfermagem que visavam à capacitação técnica de mulheres para atuarem como auxiliares dos médicos em hospitais ou, sobretudo, para trabalharem como "guardiãs da saúde" em "casas de família", não alterou imediatamente as características socioculturais das enfermeiras, embora tenham contribuído para produzir novas representações que idealizavam um novo tipo de enfermeiras, aquelas que possuíam um diploma.

A classificação da enfermagem como uma "profissão doméstica" reforçava e dava novo sentido à representação que estabelecia o cuidar dos doentes, idosos e crianças como uma função feminina. No final do século XIX, a medicina higienista propunha um novo tipo de enfermeira, que deveria ser uma mulher sadia, higiênica, intelectualmente segura e moralmente confiável. O novo tipo de enfermeira atendia às expectativas do estilo de vida higiênico adotado pelas elites cariocas, que estimulavam as mulheres e as mães a assumirem a condução dos cuidados que acreditavam garantir a saúde e o bem-estar de seus filhos, maridos e parentes idosos.

Recebido em: 29/06/2020

Aprovado em: 04/08/2020 